
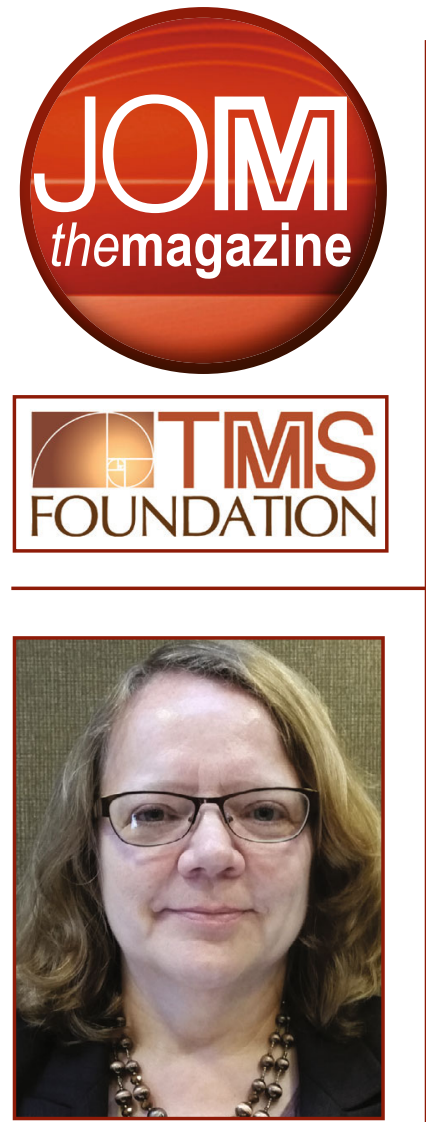

Cindy Belt

\title{
Give It Your Best Shot: Enter the 2017 TMS Materials Photography Contest
}

\author{
Lynne Robinson
}

\section{TMS Foundation: growth through giving}

This regular JOM feature provides updates on TMS Foundation activities, as well as news on opportunities for TMS Foundation support and engagement. Visit the Foundation website at www.TMSFoundation.org to learn more.

A skilled photographer can reveal beauty in the most unexpected places. Cindy Belt, Vice Chair, TMS Extraction and Processing Division (EPD), is counting on TMS members to use their photography talents to show just how beautiful the minerals, metals, and materials world can be-while also helping a good cause.

Belt is currently leading an ad hoc committee to pilot the TMS Materials Photography Contest, which she initially suggested after observing that many TMS members were also avid photographers. "It seemed that we needed a way to

\section{Fast Facts: 2017 TMS Materials Photography Contest}

\section{Find complete rules and submission form at: www.TMSFoundation .org/2017PhotoContest}

\section{Deadline: November 30, 2016 Open to all TMS professional and student members.}

Entry Fee: \$10 per photograph submitted.

All proceeds benefit TMS Foundation Division Scholarships.

\section{Prizes:}

1st place: $\$ 300$ and ribbon 2nd place: $\$ 200$ and ribbon 3rd place: $\$ 100$ and ribbon Honorable Mention: ribbon

Winning entries will be displayed at the TMS 2017 Annual Meeting \& Exhibition and published in JOM.

Images will be judged on materials relevance, aesthetics, visual impact, and creativity. display and share our members' talents," she said. Entries for the inaugural competition are now being accepted at www.TMSFoundation .org/2017PhotoContest. The deadline for entries is November 30,2016 . Proceeds from the $\$ 10$ per photograph entry fee are earmarked to support TMS Foundation Division Scholarships.

Specific rules are detailed on the photography contest's website. In general, the subject of all photographs submitted must relate to minerals, metals, and/ or materials. These can include microscopic images captured microscopes and scanning electron microscopes. Macroscopic images are encouraged as well—mining and foundry processes or metallic structures are just a few examples of potential subjects. There are no separate judging categories - all photographs submitted will be judged as one group. Images must be two-dimensional and cannot with such technologies as optical contain images of people. Color changes, enhancements, and photo editing are permitted.

"A goal of the competition is to showcase the beauty of minerals, metals, and materials," said Belt. "Many microscopic images are quite gorgeous. Our processes can be visually striking with metal flow and the heat treatment of metal. The equipment we use - both currently and in the pastis stunning. Metal is used in a variety of dramatic ways. The contest gives the photographers within TMS's membership a chance to share all of this with others, both inside and outside of our profession."

Cash prizes will be awarded to the top three images selected by a panel of judges representing each TMS technical division. These photographs, as well as those selected for honorable mention, will be published in JOM and displayed at the TMS 2017 Annual Meeting \& Exhibition, February 26-March 2, in San Diego.

Belt noted that two accomplished TMS member photographers-James C. Foley, Research and Development Manager, Los Alamos National Laboratory, and Adrian C. Deneys, Business Development Manager, Praxair, Inc - served on the ad hoc committee and were "instrumental" in developing and implementing the contest. If the competition is well-received, Belt said that future refinements could include the development of additional judging categories and other opportunities for display. "I encourage anyone who wants to share a photograph to participate," Belt said. "Even if you don't think you will win a prize, it will give you a chance to show your work to your colleagues - and it's a great way to support our division scholarships and the students that they benefit." 


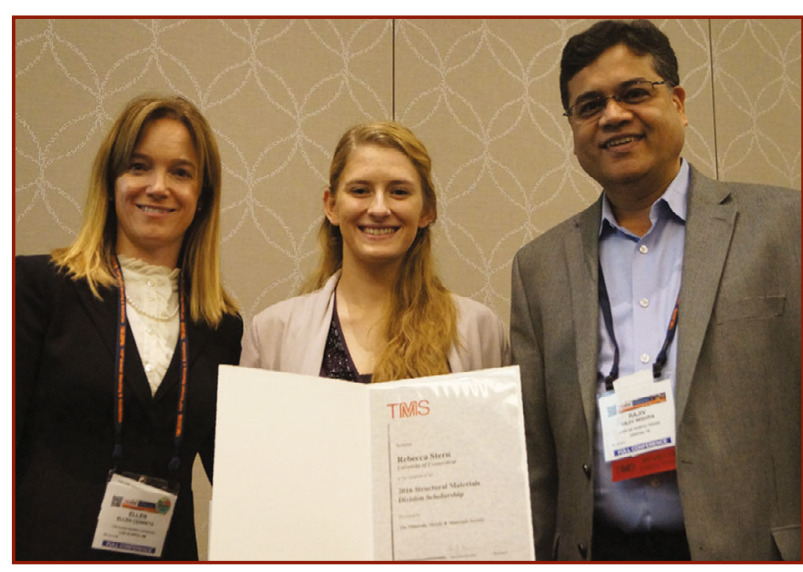

Rebecca Stern (center) is one of 240 students who have benefited from a TMS Foundation Division Scholarship since the foundation was established in 1993. Proceeds from the 2017 TMS Materials Photography Contest will be used to help ensure that more students receive this important academic support in the future. Stern, a student at the University of Connecticut, is pictured receiving her 2016 Structural Materials Division (SMD) Scholarship from Ellen Cerreta, SMD Vice Chair (left), and Rajiv Mishra, SMD Chair.

\section{TMS Foundation Update}

TMS2017 VIP Package

The TMS Foundation is now offering a TMS2017 VIP Package as a special thank you to donors contributing $\$ 2,000$ or more to the 2016 Annual Appeal.

The TMS2017 VIP Package includes:

- Concierge registration at the TMS 2017 Annual Meeting \& Exhibition, February 26-March 2, in San Diego, California. VIP donors will be able to pick up their registration materials at a convenient location, rather than waiting in the registration line

- Complimentary tickets to: TMSAIME Awards Banquet; TMS Foundation Donor Appreciation Event; a TMS Division Awards Luncheon of your choosing

- Access to the TMS Volunteer Leadership Lounge

- Thank you gift

- TMS2017 VIP Donor badge

The deadline for making your contribution count for a TMS2017 VIP Package is December 31, 2016. Donate today by visiting www.TMSFoundation .org/Contribute or contacting Mary Samsa, TMS Foundation \& Public Affairs Manager, at (724) 814-3130 or msamsa@tms.org.

\section{New Honorific Societies}

The TMS Foundation has added two new Honorific Societies to provide additional opportunities for recognition to those who have made generous donations over the course of a lifetime.

The new Titanium Society honors those who have contributed $\$ 10,000$ to $\$ 19,999$, while the Platinum Society recognizes those who have donated $\$ 50,000$ to $\$ 99,999$. They join the Silver Society $(\$ 5,000$ to $\$ 9,999)$, the Gold Society $(\$ 20,000$ to $\$ 49,999)$, and the Diamond Society ( $\$ 100,000$ or more).

New Honorific Society members for 2016 will be inducted at the TMS Donor Recognition Event on Sunday evening, February 26, at the TMS 2017 Annual Meeting \& Exhibition.

\section{Annual Appeal Match Still Available}

You still have the opportunity to double the impact of your donation to the 2016 TMS Foundation Annual Appeal through a generous fundraising challenge supported by TMS

Foundation leaders. The first $\$ 30,000$ donated during the campaign will be matched, dollar for dollar, by Lucinda and Martin Glicksman (1994 TMS Fellow), Robyn and Robert Wagoner (1997 TMS President and 2003 TMS Fellow), Garry W. Warren (TMS Foundation Board of Trustees Chair and 2011 TMS President), and Stanley M. Howard (2016 TMS President and TMS Foundation Trustee).

Help the TMS Foundation reach its 2016 Annual Appeal goal of $\$ 100,000$ by December 31, 2016. Visit www.TMSFoundation.org/Contribute today to make an online donation.
TMS Foundation Board of Trustees

Chair:

Garry W. Warren

Professor Emeritus,

University of Alabama

Past Chair:

Robert H. Wagoner

Professor Emeritus,

The Ohio State

University

\section{Executive Committee \\ Representative:}

Stanley M. Howard

Professor,

South Dakota School of

Mines and Technology

Trustees:

Carl M. Cady

Technical Staff Member, Los Alamos National

Laboratory

Hani Henein

Professor,

University of Alberta

Edward D. Herderick

Additive Technologies

Leader,

GE Corporate Supply

Chain and Operations

Elizabeth A. Holm Professor,

Carnegie Mellon

University

Alexander R. Scott

Retired TMS Executive Director

David A. Shifler

Program Officer Office of Naval Research

Secretary: James J. Robinson TMS Executive Director 